\title{
The Sims:
}

\section{Jogo Computacional como uma Ferramenta Pedagógica na Construção do Conhecimento Matemático}

\author{
Rúbia Juliana Gomes Fernandes \\ Universidade Tecnológica de Ponta Grossa \\ rufernandes@hotmail.com \\ Guataçara dos Santos Junior \\ Universidade Tecnológica de Ponta Grossa \\ guata39@gmail.com
}

\begin{abstract}
Resumo: A presente análise teve como objetivo investigar se o jogo The Sims pode favorecer a aquisição dos conhecimentos matemáticos no processo ensino-aprendizagem das situações-problemas, a partir de momentos em que os jogos computacionais possam envolver os conceitos matemáticos nos anos finais do ensino fundamental. A investigação foi realizada com alunos do $6^{\circ}$ ano do ensino fundamental numa escola da Rede Municipal de Curitiba localizada na região leste da capital, em um bairro considerado o segundo mais violento da cidade. Baseou-se na exploração realizada no laboratório de informática e nas aulas de matemática, apoiando-se na interação, como fio condutor na resolução de problemas em momentos de jogos computacionais. Sob essa ótica, a fundamentação teórica transcorrerá à luz dos estudiosos da vertente interacionista e da Educação Matemática Crítica.
\end{abstract}

Palavras-chave: Jogos. Matemática. Interação. Tecnologia.

\section{The Sims:}

\section{A Computational Game as a Pedagogical Tool for the Building of Knowledge on Mathmatics}

\begin{abstract}
The present analysis aimed to investigate if The Sims game may encourage the acquisition of Mathematical knowledge in the teaching-learning process in moments of problems situation with the computational games that involve mathematical concepts in the final years of primary education. The study was conducted with students from 6th grade of elementary school, based on the exploration carried out at the computer lab and Mathematics classes, relying on the interaction as a guide in solving problems at the moments of computational games. Under this view, the theoretical foundation will be coursed by interactionist scholars and Critical Mathematics Education.
\end{abstract}

Keywords: Games. Mathematics. Interaction. Technology. 


\section{Introdução}

O conhecimento matemático é um processo em permanente evolução, originado da necessidade do homem em transformar a sua realidade em prol da própria sobrevivência. Essa capacidade de modelar situações práticas e reais é o que impulsionou e impulsiona o ser humano a elaborar criações cada vez mais avançadas e ousadas em resposta aos seus problemas. Percebe-se a importância em entender que, a História da Matemática, no contexto da prática escolar, pode ser vista como mais um componente pedagógico, pois a partir deste entendimento, pretende-se oportunizar aos estudantes, a possibilidade de entender a natureza da educação matemática e sua importância na história da humanidade.

Nos dias atuais, o ensino da matemática está passando por um momento de análise e reflexão em relação à matemática ensinada e aprendida em âmbito escolar. A esse respeito, Bazzo (1998) pondera que todos os cidadãos devem ter acesso à leitura, compreensão e aprendizagem. Cabe perceber que para tal, é importante que os conceitos matemáticos, devam ser trabalhados conjuntamente entre as áreas do conhecimento, favorecendo desse modo, a incorporação dessas relações pelos indivíduos, levando-os a uma leitura de mundo inferindo em preceitos escolares.

Anuindo com o exposto, Skovsmose (2007, p. 208) pontua que:

[..] a ideia da importância do conhecimento matemático teve ser compreendido como uma maneira de tornar o cidadão mais crítico e menos suscetível a uma matemática invisível. Mas isso não é fácil, principalmente quando a tradição da matemática escolar parece condicionar os estudantes apenas a executar comandos predefinidos por alguém superior a ele.

Devido ao grande avanço tecnológico muitas atividades cotidianas passaram a ser realizadas por máquinas. Nesse viés, surge a "era da Informática", e com esta, as informações se difundiram em grande escala, revolucionando o modo de vida da humanidade. Desse modo, compreende-se que a educação matemática escolar precisa adaptar-se a esta nova realidade.

Ao considerar estes pressupostos, torna-se evidente a importância em explorar e apropriarse dos recursos tecnológicos direcionados a favor das práticas pedagógicas escolares, bem como na sistematização dos conceitos matemáticos em momentos de empregabilidade, como por exemplo, em situações de jogos interativos.

Ressalta-se que, somente associar conceitos estudados e compreendidos a contextos de aplicabilidade, pode ser entendido como um fator primordial, porém, talvez não seja o suficiente. Vislumbra-se que, além disto, o aluno tenha condições de utilizar os conhecimentos e habilidades matemáticas em sua vida cotidiana.

Pretende-se, ao sistematizar a prática pedagógica nessa perspectiva subsidiar e contribuir na leitura, análise e interpretação dos estudantes em ocasiões reais, nas quais haja necessidade de posicionar-se de forma crítica e decisiva.

Neste viés, compreende-se que a ação docente pode postular-se como princípio importante no processo metodológico, ao favorecer e instigar a assimilação, organização e apropriação 
dos conhecimentos pelos estudantes. Cabe ponderar, que é do professor a iniciativa em promover e gerar momentos de reflexão e ação, bem como provocar conflitos cognitivos que impulsionem e propiciem o crescimento intelectual, apoiando-se nos recursos tecnológicos.

Almeja-se que, com a inserção de jogos computacionais, estes possam favorecer os processos de aprendizagem, bem como auxiliar as práticas docentes, na tentativa de auxiliar na constituição da formação integral e legítima dos sujeitos.

Procurando responder a este questionamento, este trabalho tem como objetivo: investigar se o jogo The Sims pode favorecer a aquisição dos conhecimentos matemáticos no processo ensino-aprendizagem das situações-problemas, em momentos em que os jogos computacionais envolvam os conceitos matemáticos nos anos finais do ensino fundamental.

\section{A Tecnologia nos Ambientes Escolares}

Com a evolução da sociedade e suas necessidades, o papel da educação precisa ser repensado para que possa contribuir na constituição de um aluno que seja verdadeiramente um cidadão crítico, capaz e consciente, de modo que possa participar e intervir ativamente na realidade e no contexto social em que está inserido.

Mediante o exposto, Skovsmose (2001) reflete que a Matemática se dispõe e pretende formatar a sociedade. Este estudioso realiza análises e ponderações, ao considerar que os conhecimentos, conceitos e habilidades matemáticas se fazem cada vez mais presentes, no que tange ao desenvolvimento social.

Ainda nesta vertente, questiona-se sobre o que resta da competência matemática de uma sociedade que se apresenta altamente tecnológica. "O resto não poderia ter muito em comum com a nossa sociedade atual. Isso significa que a matemática tornou-se parte da nossa cultura" (Skovsmose, 2001 p. 99).

Nesse aspecto, a informática aplicada à educação pode ser entendida como instrumento pedagógico importante e, por consequência, auxiliar nos processos de apropriação e construção do conhecimento, promovendo novas interações e relações na tentativa de contribuir no processo de ensino e aprendizagem.

Ao apoiar-se no computador como uma ferramenta pedagógica, as atividades que eram realizadas de forma convencional podem ser realizadas em outros contextos, possibilitando ao estudante ampliar e extrapolar suas observações, análises, reflexões e conclusões.

Corroborando com o exposto, Brasil (1997, p. 31), afirma que:

[...] o uso dos recursos tecnológicos pode ocasionar significativas contribuições para se repensar sobre o processo de ensino-aprendizagem de matemática com várias finalidades: fonte de informação, poderoso recurso para alimentar o processo de ensino-aprendizagem; auxiliar no processo de construção do conhecimento; meio para desenvolver autonomia pelo uso de softwares que possibilitem pensar, refletir e criar soluções; como ferramenta para realizar determinadas atividades, emprego de planilhas eletrônicas, processadores de textos, bancos de dados e outros. 
Desse modo, compreende-se que no enfoque da educação matemática crítica os ambientes gerados por aplicativos informáticos dinamizam os conteúdos curriculares e potencializam os processos pedagógicos. Acredita-se, que estes fatores podem favorecer o surgimento de novos conceitos e de novas teorias matemáticas (Borba, 1999).

Sob essa ótica, deseja-se que os jogos educativos computadorizados possam configurar-se numa forma lúdica de propor situações-problemas, ao entender que os conhecimentos e aprendizagens matemáticas, sendo apresentadas de forma atrativa e motivadora, têm por finalidade potencializar a criatividade e iniciativa na busca de estratégias e mecanismos eficientes para resolver as situações-problemas suscitadas.

Nessa perspectiva, ao utilizar recursos pedagógico-tecnológicos no ensino fundamental, deseja-se colaborar para que os alunos sejam capazes de distinguir e aplicar diferentes fontes de informações em contextos diversos, bem como de se apropriar das relações estabelecidas, por meio dos subsídios que as ferramentas tecnológicas podem propiciar no momento da aquisição e construção do conhecimento matemático.

Desse modo, ao oportunizar a utilização dos jogos interativos nos ambientes escolares, acredita-se que essa ação ocasionará vantagens para os processos pedagógicos de ensino e aprendizagem. Pondera-se que, este recurso metodológico tem como pretensão a interação, a perspicácia, a dinamicidade em prol da consolidação e apropriação dos conhecimentos, conceitos e conteúdos matemáticos.

Ao explorar as representações e relações virtuais de maneira coerente, planejadas e sistematizadas, estas contêm grandes quantidades de informações que podem se apresentar de diversas maneiras numa relação interativa, objetiva e lógica. Contudo, exigem do jogador a concentração, estratégias e percepção das jogadas, para que os resultados das suas ações revertam-se como desejado e possam ser apreciados em tempo real.

Nesse sentido, ao pensar o processo pedagógico interventivo pautado em jogos eletrônicos no ensino da matemática, pretende-se conciliar a satisfação proporcionada pelo ato de jogar ao da utilização das tecnologias. "O ato de brincar tem-se modificado principalmente no tocante às tecnologias desenvolvidas na construção do brinquedo e, consequentemente, nas formas de brincar" (Munguba, 2010 p.39).

Sob esta vertente, os jogos eletrônicos tornam-se cada vez mais populares e de fácil acesso. Portanto, cabe às instituições educativas propiciar uma educação que contemple também o contexto tecnológico, pois se percebe que a sociedade contemporânea exige dos sujeitos competências específicas relacionadas à tecnologia.

Assim sendo, na atual conjuntura pondera-se que os indivíduos necessitam compreender e ter condições de operacionalizar com os processos e procedimentos sociais que os permeiam, em resposta a situações-problemas reais, as quais exigem do sujeito diferentes competências, como a autonomia, a iniciativa ao sentir-se desafiado em qualquer contexto, seja ele social ou acadêmico, subsidiando-se em diferentes mecanismos e estratégias para solucioná-lo, inclusive em contextos tecnológicos. 


\section{Metodologia}

A partir das questões mencionadas no tocante à educação matemática, e se os jogos interativos podem realmente favorecer as aprendizagens matemáticas que vêm ocorrendo no interior das instituições escolares, é que se pensou em estruturar este estudo investigativo. Refletiu-se, como o posicionamento do professor pode influenciar e cooperar direta ou indiretamente na assimilação e apropriação dos conhecimentos matemáticos pautando-se na tecnologia como recurso didático.

A vertente metodológica desta investigação pretende explorar o trabalho pedagógico amparando-se na pesquisa-ação ${ }^{1}$, tendo como mola propulsora o planejamento, a análise, a efetivação dos envolvidos na pesquisa.

Nesse aspecto, Moreira (2008, p.92) conclui que:

A pesquisa-ação configura-se nos ambientes escolares como um meio: a) de sanar os problemas diagnosticados em situações específicas, ou melhorar de alguma maneira um conjunto de circunstâncias; b) de treinamento em serviço, portanto, proporcionando ao professor novas habilidades, métodos para aprimorar sua capacidade analítica e o fortalecimento da autoconsciência; c) de introduzir abordagens adicionais e inovadoras no processo ensino-aprendizagem e aprender, continuamente, em um sistema que normalmente inibe a mudança e a inovação; d) de melhoramento à comunicação entre professor praticante e o professor acadêmico na tentativa de remediar a deficiência da pesquisa tradicional de dar prescrições claras; e) de proporcionar uma alternativa à solução de problemas na sala de aula.

Sendo assim, entende-se que ao aplicar o método da pesquisa-ação na vertente educacional o alicerce primordial será a junção entre a teoria e a prática como devolutiva a problemáticas existentes nos ambientes educativos. Reflete-se, assim, que esta metodologia pode favorecer significativamente o processo educativo, pois ao explorar essa vertente, buscase um caminhar indissociável entre a hipótese e o procedimento, que jamais são vistos isoladamente, quando se pretende a transformação da prática docente. Cabe destacar, que nessa concepção pedagógica é indispensável que o professor tenha muito claro o sentido e a intencionalidade da transformação que deseja impor dentro do seu contexto escolar, fatores estes que caracterizarão a metodologia da pesquisa-ação.

Para esta metodologia contou-se com a participação de 30 alunos, sendo 12 meninos e 18 meninas da Rede Municipal de Ensino do $6 .^{\circ}$ ano. A instituição escolar situa-se num bairro da periferia de Curitiba e organiza-se em ciclos de aprendizagens que prevêem o aprofundamento gradativo dos conceitos acadêmicos.

Mediante a perspectiva, os ciclos de aprendizagem visam não só uma organização educacional distinta da classificatória utilizada pelo município anteriormente, mas também direciona as práticas educacionais, para que se concretizem mudanças necessárias com relação à essência do processo de ensino e aprendizagem que se estruturam no interior das instituições. Considera-se agora, nessa temática, a temporalidade na aquisição e construção dos princípios matemáticos, em caráter contínuo e processual na formação dos discentes, fator que pode contribuir para as intervenções docentes, desde que respeitados 
os conhecimentos já constituídos para sistematizar outras práticas didáticas com o objetivo de mediar a ampliação desses conhecimentos.

Segundo Vasconcelos (2006), a organização ciclada promove o ensino focado no processo de ensino-aprendizagem, pois proporciona ao aluno um tempo maior para adquirir os conhecimentos necessários para sua progressão acadêmica, e concede ao professor uma maior flexibilidade para desenvolver o seu trabalho. Nessa concepção por ele estruturada, haverá uma preocupação mais relevante da escola com a promoção do desenvolvimento global das habilidades e potencialidades dos discentes.

Reiterando com a ideia de Vasconcelos (2006), pode-se indicar o que já estava sendo refletido nos PCNs:

Os conhecimentos adquiridos na escola passam por um processo de construção e reconstrução contínua e não por etapas fixadas e definidas no tempo. As aprendizagens não se processam como subida de degraus regulares, mas como avanços de diferentes magnitudes (Brasil, 1997, p. 43).

Percebe-se que a instituição tem uma boa estrutura educacional envolvendo professores corregentes, além dos regentes, contraturno, planos de apoio individualizado. Caso haja necessidade existe o Centro Municipal de Atendimento Especializado, com laboratórios de informática, artes e ciências, e biblioteca informatizada com atividades culturais, sala de jogos de mesa para estimular o raciocínio, e sala para práticas de expressão corporal que é utilizada para as aulas de educação física, além de canchas e quadras cobertas.

\section{Descrição do Jogo}

Ojogo denominado The Sims, também pode ser apresentado com as seguintes abreviações: TS (The Sims) ou TS1 (The Sims 1). Este é um jogo eletrônico de simulação real em duas e três dimensões, produzido especialmente para ser utilizado em ambientes computacionais pelo designer Will Wright, e sendo lançado em 2000, o jogo angariou muitos adeptos graças a sua objetividade e naturalidade.

Nele, configuram-se três momentos distintos da vida dos Sims (recém- nascido, criança e adulto); o próprio jogo oportuniza somente ao jogador que está com o personagem do recém-nascido, a opção de tornar-se criança, e também de coordenar a vida cotidiana dos demais personagens, como por exemplo: cuidados com a alimentação, trabalho, vestuário, relacionamento interpessoal, dormir, cuidar dos fazeres do lar, higiene pessoal, realizar compras de uso pessoal e para casa, bem como todas as questões que permeiam as relações condizentes com uma família.

Porém, cabe mencionar que existem algumas questões relevantes que merecem destaque no contexto do jogo. Pode-se pontuar o fato que as crianças nessa realidade virtual jamais se tornam adultos, mesmo os recém-nascidos transformados em crianças. Nessa linha de raciocínio, torna-se fundamental esclarecer que os Sims adultos nunca alcançam a terceira idade, sempre permanecem adultos, porém não velhos. Tem-se, também a situação de não haver fins de semana nesse contexto, e que os Sims devem frequentar a escola todos os dias, haja vista que não existem sábados e domingos. É importante ter ciência, que não se 
pode controlar os Sims visitantes, mas que na perspectiva do jogo, torna-se primordial a interação com estes, vislumbrando constituir uma vida social harmoniosa.

Entende-se que The Sims pode ser um jogo extremamente interessante, pois, pretende refletir aspectos corriqueiros e cotidianos da vida dos sujeitos em geral, como por exemplo: relacionamentos familiares e sociais, afazeres do dia a dia, rotinas escolares e outras questões de ordem prática que permeiam a vida real, sem ter que lançar mão de ficção e fantasia no intuito de entreter e prender a atenção dos jogadores.

Sob esse aspecto, compreende-se que o jogo de simulação, ou jogos de estratégias como o The Sims pode ser categorizado como um jogo eletrônico podendo ser aplicado em videogames e computadores. Desataca-se, ainda, que entre os jogos computacionais alguns deles, detêm-se a simular o mundo real, e outros o mundo fantasioso. The Sims enquadra-se nessas duas vertentes: da mesma forma que retrata a realidade não deixa de lado o fictício, a imaginação.

Portanto, pode-se ponderar que no momento da execução dos jogos de estratégias pode-se suscitar uma variedade de alternativas, hipóteses e possíveis desígnios, sendo de total responsabilidade do jogador a melhor escolha, mediante as opções de jogadas disponíveis, objetivando alcançar a vitória ao término do jogo. Pode-se, no entanto, optar em administrar uma situação que o jogador julgue ser conveniente, ou até mesmo na combinação das opções que estão à disposição, na tentativa de indução do melhor resultado, ou em ainda criar um mecanismo de jogo que instigue os demais competidores a criar as jogadas e situações simplesmente para serem gerenciadas.

\section{Procedimentos Metodológicos}

Este estudo apoiou-se no método da pesquisa-ação, em que os discentes e docentes se envolvem diretamente numa relação dialógica e interativa, objetivando constituir e ampliar seus conhecimentos matemáticos na busca de formar um cidadão reflexivo e analítico.

A intervenção pedagógica ocorreu durante três meses, durante as aulas de matemática e no laboratório de informática. A pesquisadora promoveu uma exposição inicial das atividades propostas, utilizando data show para realizar a apresentação do jogo The Sims aos discentes: sua origem, regras, objetivo e dinâmica.

Inicialmente a exposição abarcará uma apresentação visual do jogo. Mencionou-se, que o jogo foi confeccionado pela empresa Maxis e disseminado pela Eletronic Arts (EA), constituindo um simulador onde o jogador cria seus próprios personagens, num "reality show" virtual que é baseado na vida real, bem como sua origem e as regras de uma forma sucinta. Inicialmente os alunos tiveram um momento de exploração livre do jogo no laboratório de informática, para que pudessem apropriar-se das estruturas gráficas, tecnológicas e, mais tarde, as propriedades e conceitos matemáticos. Concomitantemente a esses movimentos, a pesquisadora esteve capacitando 6 alunos da turma que foram denominados de multiplicadores, com a função de contribuir com a pesquisadora nas aulas que ocorreriam no laboratório de informática auxiliando a todos os alunos durante o jogo. 
Desse modo, o jogador tem como objetivo escolher e liderar a vida dos personagens dentro do jogo, no caso os Sims, suprindo suas necessidades básicas, como por exemplo, a alimentação, vestuário, trabalho, bem como as relações sociais, financeiras, familiares e acadêmicas.

Com base no exposto, os alunos criaram a família Sims (personagens). De início realizaram a análise e a compra do terreno, onde construíram as casas; em seguida deveriam adquirir os mobiliários e as especificidades que compõem um ambiente familiar. Cabe ressaltar que os participantes sabiam que ao esgotarem seus recursos financeiros, precisavam procurar um trabalho, pois deveriam ter proventos para se sustentar e suprir suas necessidades elementares.

No momento seguinte, os estudantes criaram em sala de aula um croqui da planta da casa que eles pretendiam construir, bem como suas especificidades, para que, sequencialmente, pudessem aplicar na projeção computacional as informações hipotetizadas e sistematizadas a partir dos croquis.

Ressalta-se, que no laboratório de informática tiveram a oportunidade de observar e analisar a viabilidade do projeto. Baseando-se nos conceitos de área, perímetro e relação custo-benefício que empregaram para realização do proposto, além da localização e movimentação de objetos, estimativas com as medidas convencionais, estabeleceram relações do sistema monetário brasileiro, entre outros conhecimentos, que serão descritos na sequência.

Nesse aspecto, ao jogar The Sims, retrata-se a vida real cotidiana no formato computacional potencializando habilidades sociais, intelectuais e acadêmicas. Sob esta ótica, as relações matemáticas ficam perceptíveis, pois se faz necessário utilizar e operacionalizar com os conhecimentos reais e matemáticos, tais como:

- Localizar e movimentar objetos em mapas, croquis e representações gráficas.

- Constituir relações entre unidades de medida de tempo e resolver problemas.

- Deduzir cálculos, perímetro, e estimativa de área de figuras planas.

Instituir relação com o sistema monetário em situações-problemas a serem resolvidas envolvendo as operações aditivas, subtrativas, multiplicativas e divisórias, além do raciocínio lógico dedutivo sistematizado que permeou esse processo interventivo.

Sistematizar uma retrospectiva das atividades realizadas em conjunto e individuais, elencando os conceitos acadêmicos com os quais trabalhamos nas circunstâncias eletrônicas, tais como: fatores climáticos, leitura e escrita, resolução de problemas, cálculos de áreas, leitura gráfica, leitura de mapas, raciocínio lógico, sistema monetário, adição, subtração, multiplicação e divisão.

- Relacionar os conceitos matemáticos sistematizados e apresentados no decorrer das aulas de matemática com os conceitos observados nos momentos de jogo, ponderando nesse momento que as estruturas matemáticas apresentadas no contexto escolar, não são desconectas com a realidade, um exemplo disso é a aplicabilidade durante o jogo.

- Resolver situações-problemas oriundas de circunstâncias vivenciadas durante os momentos de jogos, que necessitem da aplicação dos conceitos relacionados nos momentos anteriores. 
- Resolver situações-problemas apresentadas no livro didático dos alunos envolvendo os conceitos explorados e sistematizados durante esse processo interventivo.

- Estabelecer relações de cooperação e socialização entre docente e discente, bem como discente e discente nos momentos de jogo.

Estabeleceu-se conexão entre as estruturas de conceitos e conhecimentos matemáticos que estavam presentes nos momentos de jogo e que foram retomados e sistematizados em sala de aula. Fato primordial para que os alunos compreendam como a matemática e seus conceitos estão presentes em diversos contextos da vida cotidiana das pessoas e, por vezes, os indivíduos nem percebem. Conseguiram também, visualizar e entender a empregabilidade e utilidade das informações, consideração e apropriação dos conceitos matemáticos ensinados no decorrer dos processos acadêmicos.

Nessa perspectiva, em sala de aula, os alunos resolveram situações-problemas diversas, envolvendo estruturas matemáticas exploradas e sistematizadas anteriormente em circunstâncias de jogo, conforme se observa nas figuras 1 e 2 a seguir.

Mediante o exposto, Vygotsky (2000) reflete que, ao introduzir o lúdico nos contextos educacionais, acredita-se que quando esses recursos pedagógicos são pensados e organizados podem contribuir e influenciar enormemente o desenvolvimento cognitivo, social e intelectual das crianças. Pondera-se, que os jogos interativos tecnológicos propiciam aos partícipes, aprender a atuar e lidar com a sua curiosidade, perspicácia, análise e reflexão adquirindo iniciativa e autoconfiança.

Para D'Ambrósio (1989), o ensino da matemática pode valer-se dos jogos computacionais como ferramenta didática a favor do processo pedagógico. Percebe-se que essa ferramenta está se ampliando e tomando proporções cada vez maiores nos espaços escolares; faz-se necessário que o professor adote uma postura reflexiva, pois é preciso rever, repensar e reorganizar sua prática e posturas docentes frente a seus desafios diários.

Ainda nessa perspectiva, Brasil (1997), reitera que os recursos computacionais podem ser compreendidos como uma possibilidade didática para subsidiar as relações educacionais ao tratar do ensino, como fonte de pesquisa, informação e aprendizagem. Vislumbrandose desse modo que o sujeito possa ter a possibilidade de refletir sobre um mesmo assunto sob diversas óticas.

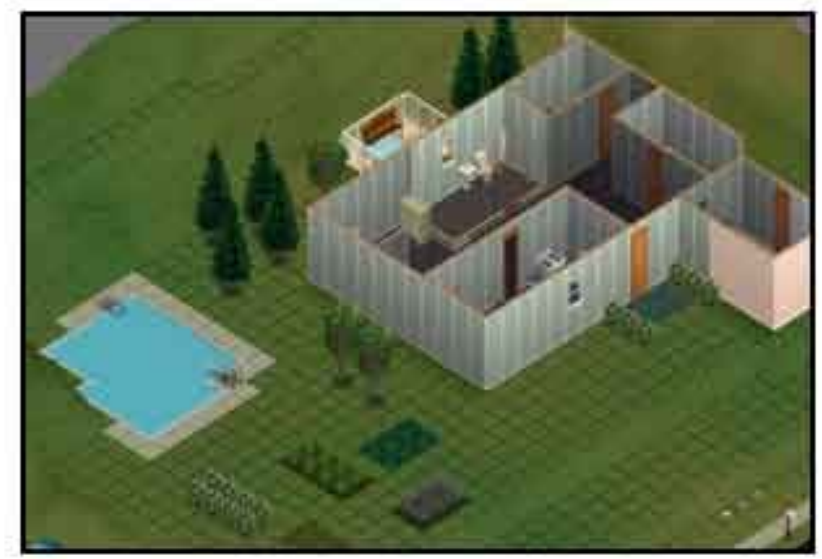

Figura 1. Início da construção da casa dos Sims Fonte: Imagem do Jogo The Sims. 


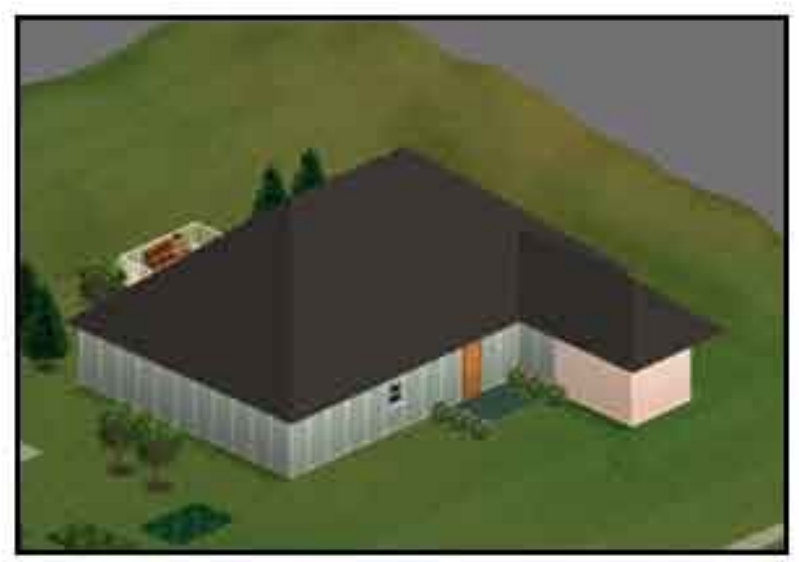

Figura 2. Finalização da casa dos Sims Fonte: Imagem do Jogo The Sims.

Sendo assim, entende-se que há uma real necessidade em compreender os novos paradigmas educacionais que se configuram diariamente na sociedade, no qual a informática está fortemente inserida. Esses aspectos implicam o repensar do papel da escola nos processos de ensino e aprendizagem e o redimensionamento do papel que o professor precisa desempenhar no interior da sala de aula.

\section{Apresentação e Análise dos Resultados}

A partir dos resultados obtidos, pôde-se notar que os alunos sentiram-se satisfeitos em saber que numa atividade de entretenimento conseguiram associar, atrelar a importância da disciplina do contexto escolar às situações rotineiras do seu cotidiano considerando-as agradáveis.

Observou-se que algumas atitudes positivas foram detectadas nos alunos, com relação ao processo de ensino-aprendizagem, como por exemplo: compreenderam que para realizar as atividades dirigidas no contexto do jogo e em sala de aula, torna-se fundamental efetivar leitura compreensiva com cautela e atenção, para interpretar as consignas estabelecidas; perceberam a necessidade da leitura significativa na resolução de situações-problemas; pontuaram a necessidade em instituir relações de interação e diálogo durante a realização das tarefas em diversos contextos; participaram ativamente na resolução das situaçõesproblemas propostas sistematizando conceitos explorados ao longo da intervenção, além das estratégias de resolução; notaram que nem sempre os algoritmos são a única resposta possível para realização da situação-problema existente; pontuaram que é importante reportar-se a situações similares para apoiar-se, para resolver novos desafios; identificaram que as estratégias e mecanismos utilizados no laboratório de informática nas situações de jogo, podem aplicar as informações e conhecimentos em outros momentos; notaram que ao debater, ponderar, coletivamente favorece a compreensão do que deve ser efetivado para resolver a situação-problema em questão; aprenderam a expor suas ideias e respeitar a dos outros com criticidade.

Aluno " $L$ " do $6^{\circ}$ ano relatou que "achou divertido, engraçado e muito educativo, pois podemos montar casas, formar famílias e aprender a ter um bom futuro na vida." Houve uma reciprocidade entre os conteúdos desenvolvidos em sala de aula e no laboratório de 
informática, em circunstância mais desafiadora e estimulante para os alunos e professor. Logo, o aluno "M" já disparou: "Nossas aulas podiam ser sempre desse jeito, professora. Assim gostei muito das aulas de matemáticas, antes eram meio sem graça". Concluindo esse argumento, afirma o aluno " $R$ ": "agora eu consegui enxergar onde posso utilizar os conceitos matemáticos, além das operações como adição, subtração, divisão e multiplicação".

Sob essa ótica, constatou-se que é primordial que haja uma relação interativa amparada nos recursos tecnológicos, almejou-se proporcionar a analogia, a compreensão e a construção legítima dos conceitos matemáticos e, em especial, aguçar e excitar o raciocínio lógico dedutivo frente aos recursos tecnológicos e aos princípios matemáticos.

Conforme Barreto (1994), a informação sintoniza o mundo, as tecnologias estão a cada dia apresentando-se nos mais diversos formatos e usos no cotidiano dos sujeitos, constituise como um agente importante de transformação da sociedade, e acredita-se que esses fatores podem exercer grande influência no processo ensino e aprendizagem.

Assim, pode-se dizer que os encontros pautaram-se na vertente interacionista, os discentes são partícipes colaborativos, cabendo-lhes elaborar, apontar estratégias e verificar que sua viabilidade, constituiu o respeito e tolerância mutuamente entre os pares, além de ratificarem uma postura analítica, ponderada, investigativa e criativa, bem como significaram os conceitos sistematizados em âmbito escolar, extrapolaram observando que estes são conhecimentos escolares e também sociais.

Sendo assim, os estabelecimentos educacionais podem ter preponderante importância para subsidiar a formação dos sujeitos que se pretende formar "críticos, reflexivos, capazes de integrar-se e interagir em sociedade" (Pinheiro, 2007).

Nesta perspectiva, Brasil (1997) norteia que a prática pedagógica deve proporcionar uma aprendizagem significativa com relação à matemática, ou seja, o eixo desencadeador de conceitos, ideias e métodos matemáticos, não devem ser a definição e alguns exercícios de aplicação mecânica e operatória imediatas. Deve-se propor situações-problemas contextualizadas ou mais familiares possíveis, abordando os elementos citados anteriormente durante a resolução.

Nesta ótica, os discentes foram provocados a instituir, elaborar, amparando-se na criatividade e em experimentos já vividos em distintos contextos sociais, para desenvolver uma estratégia, um mecanismo como resposta, portanto estruturando uma relação interativa. Deseja-se que, colaborativamente, professor e aluno pensem, reflitam e analisem, na tentativa de traçar possibilidades a serem consideradas na busca de respostas e, nesta situação, posicionem-se ativamente, e não, passivamente.

Sob esse aspecto, Becker (1993), pondera que o conhecimento pode ser conduzido para o aluno como configuração ou estrutura global, e não só como conteúdo desvinculado da realidade. Esse estudioso pauta-se na concepção epistemológica na qual os indivíduos, ao ingressarem no ambiente escolar, já trazem consigo conhecimentos e informações do senso comum do meio físico e social.

Assim sendo, a atuação pedagógica docente legitima as vertentes teóricas e epistemológicas, na qual o sujeito é primordialmente influenciado e sofre a ação do meio físico e social ao qual está inserido. 
Portanto, Bakhtin (2006) menciona que o homem precisa se comunicar, transmitir significados, e buscar compreensão, ou seja, dialogar consigo e com os demais, numa interação incessante, permanente e indispensável.

Logo, percebe-se a importância de possibilitar, por meio da prática docente, uma educação com significação, na qual os sujeitos devem ser considerados como seres únicos, situados e pertencentes a um contexto social. Ao analisar e refletir sobre esses fatores, o docente poderá realizar enunciações pensadas, refletidas e perspicazes ao pretender por meio delas, contribuir na constituição do sujeito crítico e autônomo capaz de interagir e resolver problemas em diversas circunstâncias.

\section{Considerações Finais}

A pesquisa teve a intenção de investigar se o jogo The Sims pode favorecer a aquisição dos conhecimentos matemáticos no processo de ensino-aprendizagem em situações-problemas, em momentos de jogos computacionais que envolvam os conceitos matemáticos nos anos finais do ensino fundamental, como e de que maneira estes elementos estabelecem relações importantes entre a matemática e a tecnologia.

O impacto das novas descobertas tecnológicas é atual e, por sua vez, acarreta inúmeras mudanças sociais e na educação, produzindo transformações na natureza do saber. Portanto, o professor também precisa estar ciente dos novos espaços de aprendizagem que estão surgindo, principalmente no mundo em que seu aluno está inserido.

Desse modo, novas formas de acesso ao conhecimento, em especial nos ambientes virtuais, começam a se consolidar nas instituições escolares. Os jogos, chats, ambientes virtuais, entre outros, vêm despertando grande interesse dos alunos que passam horas em frente ao computador ou em lan houses com esses entretenimentos.

Esta geração pode ser vista como tecnológica, nestas atividades sistematizadas o aprender a interagir, a operacionalizar e executar as proposições dos jogos eletrônicos pode favorecer as práticas educativas, pois ao jogarem precisam elaborar e criar mecanismos eficientes para resolver cada problema existente nas fases do processo.

Desse modo, a resolução de problemas em ambientes virtuais pode ser uma alternativa metodológica que permite a aprendizagem dos alunos. Devido à diversidade dos mesmos, a matemática pode estar mais próxima da realidade do aluno e de seus interesses. A acentuada dificuldade dos alunos em relacionar a matemática com atividades práticas do seu cotidiano foi o que motivou a realização desse trabalho, pois, percebeu-se que os alunos sentiam muita dificuldade em atrelar a matemática acadêmica à matemática da vida.

Nesse viés, esta intervenção pautou-se numa metodologia interativa nas aulas de matemática, de modo a aliar os conteúdos matemáticos com um recurso tecnológico como o jogo computacional The Sims, e também tornar as aulas de matemática mais produtivas.

Assim sendo, ressalta-se que o objetivo investigativo da pesquisa foi parcialmente atingido, porém pondera-se que ainda há muito a ser pesquisado e investigado na perspectiva que o jogo computacional pode beneficiar a aquisição dos conhecimentos matemáticos no 
Rúbia Juliana Gomes Fernandes - Guataçara dos Santos Junior

processo ensino-aprendizagem em situações-problemas, nos momentos de jogo que envolve o ensino da matemática nos anos iniciais do ensino fundamental, desde que o professor dinamize sua prática didática e extrapole os espaços escolares para os contextos vividos no cotidiano dos educandos. 


\section{Nota}

1 A pesquisa-ação é um tipo de pesquisa participante engajada que procura unir a pesquisa à ação ou prática, isto é, desenvolver o conhecimento e a compreensão como parte da prática. É, portanto, uma maneira de se fazer pesquisa em situações em que também se é uma pessoa da prática e se deseja melhorar a sua compreensão (Engel 2000, p.182).

\section{Referências}

Almeida, Paulo Nunes. (1998) Educação Lúdica: Técnicas e Jogos Pedagógicos. 9. ${ }^{a}$ ed. São Paulo: Loyola.

Bakhtin, M. (2006 ) Marxismo e filosofia da linguagem. 12.a ed. São Paulo: Hucitec.

Barretos, A. A. (1994) A questão da informação. São Paulo em Perspectiva: Fundação Seade, v.8, n.4, p.1-10.

Bazzo, Walter Antonio (1998): Ciência, Tecnologia e Sociedade e o contexto da educação tecnológica. Florianópolis, Edufsc.

Bittencourt, J.R. Giraffa, L.M.M. (2003) A Utilização dos Role-Playing Games Digitais Processo de Ensino-Aprendizagem. Ppgcc/Pucrs. (Relatório Técnico)

Borba, M. C. (1999) Tecnologias da informática na educação matemática e reorganização do pensamento. In: BICUDO, M. A. V. (org). Pesquisa em educação matemática: concepções e perspectivas. São Paulo: Unesp.

Curitiba. (2010) Secretaria Municipal da Educação. Critérios de Avaliação de Matemática. Curitiba, Paraná.

D’ambrósio, U. (1989) Da realidade à Ação: Reflexões sobre Educação e Matemática. Campinas. SP: Summus/Unicamp.

ENGEL. G.I. (2001) Educar Curitiba. Editora da UFPR, n. 16, p. 181-191. Editora da UFPR.

Moreira, H.; Caleffe Gonzaga.; L. (2008) Metodologia da pesquisa - para o professor pesquisador. $2^{\mathrm{a}}$ ed. - editora DP\&A/Lamparina.

Munguba, M. C. (2011) Jogos Eletrônicos: apreensão de estratégias de aprendizagem. Disponível em: <www.unifor.br/hp/revista_saude/v16/artigo7.pdf>. Acesso em: 03/09/ 2011.

Parâmetros Curriculares Nacionais de Matemática: Secretaria de Educação Fundamental (1997) - Brasília: Mec/ Sef.

Pinheiro, N. A. M; Silveira, R. M. C. F; Bozzo, W. A. (2009) Revista Iberoamerican de Educación: O contexto científico-tecnológico e social acerca de uma abordagem crítico reflexiva: perspectiva e enfoque. Santa Catarina, N. 491. p, 1-25, mar.

Skvsmose, O. (2001) Educação matemática crítica: A questão da democracia. Campinas, SP: Papirus.

. (2006) Educação matemática crítica: A questão da democracia. 3. ${ }^{a}$ ed. São Paulo: Papirus. Papirus.

(2008) Desafios da Reflexão: Em educação matemática crítica. Campinas: 
Becker, P. (2001) Leitura entre o mágico e o profano: os caminhos cruzados de Bakhtin, Benjamin e Calvino. In: Faraco, C. A.; Tezza, C.; Castro, G. (Org.). Diálogos com Bakhtin. 3. ${ }^{a}$ ed. Curitiba: Editora da UFPR.

Stalder, R. C. L. (2003) Produção, leitura e compreensão do texto sala-de-aula. Dissertação (Doutorado) - Faculdade de Ciências e Letras de Assis (UNESP). São Paulo.

The Sims. (2009) Softwares, Maxis. Distribuído pela Eletronic Arts (EA): 3. ${ }^{a}$ ed.

Vasconcellos, C. S. (2006) Planejamento: projeto de ensino-aprendizagem e projeto político- pedagógico. 14. ${ }^{\mathrm{a}}$ Ed. São Paulo: Libertad.

Vygotsky, L.S. (2000) Pensamento e Linguagem. São Paulo: Martins fontes. 